\title{
Teoria e Prática no Teatro do Pequeno Gesto: Dramaturgia e Editoria da revista Folhetim
}

\author{
Fátima Saadi
}

A atividade artística é um terreno movediço para quem dela procura se aproximar apenas pela via conceitual ou apenas pela atividade prática. Ao colocar em jogo, sem precedência ou hierarquia entre estas duas instâncias, o sensível e o inteligível, a obra de arte requer uma aproximação capaz de perceber e valorizar tal imbricaçáo.

Parece simples, mas não é. Não é óbvia essa complexa natureza da obra de arte nem para os criadores nem para os fruidores.

Até meados do século XVIII, a filosofia abarcou a maior parte dos saberes, entre eles a reflexão sobre a obra de arte, sua natureza, seu interesse para o homem e para a vida em sociedade. Platão bane o artista da República, na medida em que a obra de arte distancia o cidadão da verdade, objetivo máximo de todo aquele que quer abandonar o senso comum e enveredar pelas sendas da filosofia, o amor do saber. Para Platão, a arte não tem utilidade alguma na ascese necessária para o acesso ao reino das Idéias. Ao contrário, para empreender esta caminhada, é preciso esquecer aquilo que finca o homem no mundo material: o sensível, a aparência. $\mathrm{Na}$ concepção platônica, a obra de arte é, prioritariamente, imitação, cópia, reflexo da aparência, estando assim distante três níveis do logos, do mundo das Idéias.
Aristóteles reconhece a obra de arte como potência lógica, capaz de veicular juízos verdadeiros, embora não universais. Para ele, a obra não imita a natureza, mas completa-a, realizando, pela mão do homem, o que a physis não realizou.

Em 1750, Baumgarten cunha o termo estética para designar a parte da filosofia que se dedica ao pensamento sobre a essência do belo, mas só com Kant esta reflexão ganhou foros de cidadania. No bojo do Iluminismo, que teve como corolário indiscutível a entronização do indivíduo como categoria sociológica fundamental, Kant elaborou três dos conceitos ainda hoje seminais para a discussão sobre arte. O primeiro deles é a formulação do belo como juízo reflexivo, e não como mero reflexo ou imitação da natureza. $O$ segundo é a noção de que existe uma relação de adequação entre juízo estético e sujeito, entendido aqui não como sujeito particular, mas como natureza subjetiva. $\mathrm{O}$ terceiro é a idéia de que o juízo estético, como o juízo teleológico, tem uma finalidade, mas, ao contrário deste, cuja finalidade é orgânica e objetiva, o juízo estético tem finalidade moral: o agrado desinteressado. Daí ser impossível colocar o estético a serviço de fins alheios a ele.

A partir de então, a contestação das poéticas normativas, a relação que o artista estabe-

Fátima Saadi é pesquisadora, dramaturgista do Teatro do Pequeno Gesto e Editora da revista Folhetim. 
lece com o real em seu processo criativo, os valores propriamente artísticos de uma obra, a relaçáo do fruidor com o objeto artístico e a função da arte na sociedade parecem ser os grandes eixos a partir dos quais a reflexão estética se desenvolve.

Com o movimento romântico, inaugurase a perspectiva propriamente moderna a respeito da obra de arte e a reflexão sobre o fazer artístico se torna, manifestamente, o mote principal da criação. A reflexão crítica, que a modernidade enfatiza já no próprio processo do fazer artístico, torna-se parte importante da arte e evidencia tanto a perda do sentido unitário do mundo - e, conseqüentemente, da arte, da qual fala Gerd Bornheim (1998) - , quanto a voluntária incompletude da obra, como assinala Argan (1993).

No caso do teatro ocidental de linhagem greco-cristã, tanto seu desenvolvimento quanto a reflexão sobre sua natureza, sua estrutura e suas principais manifestaçōes sofrem uma primeira clivagem entre texto e espetáculo.

Reafirmando que só uma série de malentendidos e simplificaçóes na leitura da Poética de Aristóteles podem fazer dela a consignação do desprezo do filósofo pelo espetáculo, acreditamos, no entanto, poder compreender a precedência atribuída à escrita dramática pelas poéticas normativas à luz do modelo platônicocristão que, por longo tempo, regeu o mundo: a superioridade da Idéia sobre o sensível justifica a desvalorização da concretização do espetáculo. No belo texto Sobre a paisagem, Rilke afirma, com humor, que, para a arte cristã, só existem roupas, os corpos servindo apenas para arder no inferno.

A articulação cênica que leva em conta todos os elementos do espetáculo, sem atribuir precedência absoluta ao texto, só começa a se configurar a partir de meados do século XVIII, quando a abstração das relaçóes matemáticas cede vez à observação da natureza, no bojo do processo que culmina com a substituição do paradigma cartesiano pelo paradigma newtoniano, que tem a física como eixo. Simultanea- mente, o interesse da Enciclopédia por todos os fazeres humanos valoriza o aspecto artesanal das artes plásticas, antes depreciadas justamente pela evidência deste fazer manual. Se a crítica de artes plásticas de Diderot hoje nos parece risível, porque na maior parte do tempo dedica-se a descrever a obra, ou seja, a transcrever com palavras a estrutura e a fatura do quadro, não se pode deixar de ler neste procedimento o imenso interesse que ele tem pelo que é propriamente pictórico na pintura.

A partir de Lessing, o teatro pode então refletir sobre sua natureza de arte espácio-temporal, jogando com suas relaçóes com as outras artes e com os elementos destas outras artes. Partindo do Laocoonte, podemos traçar uma linha - sinuosa, bem-entendido - que deságua no simbolismo, em Appia e em Craig.

Uma segunda clivagem nos aparece entre o que se convencionou chamar de a teoria e $a$ prática teatrais. Acho que isto é o que mais nos interessa discutir neste momento, devido aos preconceitos que paralisam um diálogo que poderia ser extremamente produtivo entre criação e reflexão. Evidentemente que, sobrenadando no terreno movediço da criação teatral, aparece-nos a crítica. Gerd Bornheim, em sua interessante coletânea Páginas de filosofia da arte (1998) - especialmente no ensaio "Gênese e metamorfose da crítica" -, relaciona a necessidade da crítica, em primeiro lugar, à perda do sentido unitário do mundo a partir da progressiva dissolução do princípio religioso que vigorou, tant bien que mal, até o Iluminismo e, em segundo lugar, à crise do conceito de representação artística como imitação da natureza, que ecoa a crise da representação como adequação do conceito ao real.

A história da reflexāo sobre a arte torna evidente a dificuldade de compreensão da tensão entre o pensamento e sua manifestação estética na obra, o que se evidencia também na dificuldade de compreensão da relação entre a obra e seu fruidor. A própria filosofia moderna, que reconheceu, com Kant, o domínio do sensível como digno de reflexão, tem oscilado, ao 
longo do tempo, entre fazer da arte exemplo, manifestação do pensamento, como em Hegel, por exemplo (que reitera a superioridade do logos sobre o sensível), e entronizá-la como modelo para a atividade reflexiva, como em Heidegger, tendo talvez os fenomenólogos alcançado um ponto de equilíbrio no que diz respeito à apreensão da obra de arte pela reflexāo filosofica.

No domínio crítico, a obra de arte tem sido considerada como reflexo das aparências, como índice da perfectibilidade do real, como meio de divulgação das idéias dominantes, como manifestação do espírito de uma época, como reflexo da infra-estrutura econômica da sociedade, como crítica do real, como arma para a transformação do real, como criadora de sentidos para o real, como denúncia da falta de sentido do real.

Os diversos modos de abordagem da obra de arte têm oscilado, de maneira geral, entre privilegiar o conteúdo, suas motivaçôes e ramificaçōes, e ater-se à análise da forma. Como antídoto à crítica impressionista, alguns estudiosos limitam-se à descrição do que vêem, apostando numa utópica isenção do olhar, sistematizada pela semiologia que disseca exaustivamente a estrutura da obra, objetivando demonstrar que nenhum sentido a ela preexiste e que, do ponto de vista estético, só interessam os sentidos por ela criados. A essas correntes veio juntar-se, mais recentemente, a estética da recepção, que enfatiza, na análise da obra, as variáveis que o processo de fruição acarreta.

No caso do teatro, que apresenta, por meio de atores, as relaçóes entre os homens e o mundo, a reflexão sobre a representação, sua natureza, sua amplitude e suas consequêencias torna-se essencial. Claro que estas discussões são fundamentais em qualquer domínio da arte, no entanto, a aparente co-materialidade da cena $\mathrm{e}$ do mundo, que preside, segundo o senso comum, especialmente a relação entre ator e personagem, obrigam-nos, de saída, a esconjurar $o$ fantasma da naturalidade da criação teatral.

Em cena, há sempre um fundo falso. Levando ao limite 0 argumento, poderíamos dizer que, em cena, nada é, tudo representa. Em cena, um homem não $\varepsilon$ apenas um homem, ele representa um homem. A representação cênica, no entanto, não se dá por adequação, forma de relação que une, na filosofia clássica, o conceito e o real, apesar da ambigüidade da linguagem. Grosso modo, pode-se dizer que a representaçáo por adequação tem como objetivo a verdade (que o sujeito autentica por meio de juízos de valor) e que a relaçáo estabelecida entre o conceito e aquilo que ele representa é biunívoca. A representação cênica escapa do âmbito da verdade e da adequação, no entanto, um plano de funcionamento ôntico é criado pela narrativa cênica e, nele, a existência é regida por outras leis e se apóia na multivalência da linguagem artística, na multiplicação de sentidos que é sua marca constitutiva.

Para compreender melhor esta operaçāo, podemos nos valer dos estudos da semiologia, táo bem desenvolvidos, no domínio do teatro, por Anne Ubersfeld 1 . Supondo que seja possível isolar um signo no âmbito da representaçáo cênica, este signo apresentaria um caráter, por assim dizer, monstruoso, ao ser dotado de um triplo referente: o mundo do espetáculo no qual se insere; o mundo da ficçáo (da trama) do qual faz parte e o mundo extra-cênico que nos abarca a todos. Os sentidos construídos por este signo dependem tanto de sua posição no interior do conjunto de signos do espetáculo (aí incluído o texto), quanto da relação do espetáculo com o mundo, que é mediada, é evidente, pelo

I Ver especialmente sua trilogia Lire le théâtre, volumes I, II (L'école du spectateur) e III (Le dialogue de théatre) - os dois primeiros publicados pelas Éditions Sociales (respectivamente em 1978 e 1991) e o terceiro pelas Éditions Belin, em 1996. 
espectador. O exemplo da coroa usada por Lear na encenação de Strehler, de 1974, pode sintetizar o raciocínio: o objeto coroa é reconhecido em função das coroas do mundo real; responde ao texto de Shakespeare, que conta a história de um rei e, por ser de papelāo, como as coroas de carnaval, expressa a concepção do espetáculo a respeito do personagem e da realeza de um modo geral. Numa interessante inversão de perspectiva, Anne Ubersfeld propóe que se leia o signo teatral criado pelo espetáculo como o referente do signo textual e do objeto real, o que cria uma espécie de curto-circuito nas tentativas de enquadrar o espetáculo no regime da representação/imitação do real extra-cênico.

Mas é, como dizíamos, no âmbito da atuação que a não-naturalidade do trabalho é mais difícil de ser percebida e aceita. Tanto porque o senso comum acredita na "verdade" dos personagens quanto porque os próprios atores acreditam na "verdade" das suas emoçôes e na adequação delas ao personagem que representam. ${ }^{2}$ Nos demais domínios do espetáculo teatral, a crise do fundamento de que falava Gerd Bornheim repercutiu de forma sensível, originando procedimentos de ruptura narrativa que, de modo geral, não atingiram o trabalho do ator, ressalvadas algumas exceções, como o trabalho de Tadeusz Kantor com a trupe Cricot 2, por exemplo.

\section{Folhetim: Um olhar à distância}

A necessidade de pensar o teatro liga-se a estas questóes que procuramos sobrevoar e interessa a todos os que estão envolvidos na criação, no estudo e - por que não? - na recepção do espe- táculo. Nos últimos vinte anos vem se esboçando, no Brasil, um grande interesse pela qualificação acadêmica dos profissionais de teatro. Deixando de lado o problema da inadequação dos métodos de avaliação dos órgãos financiadores de pesquisas, que aplicam às artes critérios inspirados na produção científica, é preciso reconhecer que a produção de bibliografia nacional, em nossa área, cresceu de forma animadora.

No entanto, ainda se verifica um hiato entre a produção acadêmica, de cunho mais propriamente historiográfico, e a atividade da criação teatral, o que não é um problema exclusivamente brasileiro. Agrava-o, entretanto, a ausência, nos órgãos de imprensa do país, de uma atividade crítica capaz de colocar em jogo o sentido do teatro, em lugar de apenas somar os pontos atribuídos a cada um dos elementos do espetáculo, julgado de per se, para obter o conceito final pespegado à montagem. Com honrosas exceçóes, a crítica se limita, em geral, ao comentário de espetáculos no calor da hora, encarando cada uma das produçôes como uma mônada isolada do restante do universo teatral, o que se reflete no método utilizado para a análise dos espetáculos.

Evidentemente, a tarefa de pensar o teatro não será esgotada por nenhuma destas frentes, ao contrário, é preciso que suas iniciativas se multipliquem, se superponham, estabeleçam diálogos produtivos. Barthes considerava que "o teatro é a prática que calcula o lugar olhado das coisas" (1982, p. 86). Isto supóe uma distância entre o palco e a platéia, mas, mais que isto, uma distância reflexiva entre o criador $e$ sua obra.

2 Observo que a necessidade de escapar da atuação realista-naturalista desencadeou em profissionais de teatro ocidentais um enorme interesse pelas manifestaçōes teatrais do oriente e de culturas não européias: o estranhamento da forma parece funcionar como amuleto contra o predomínio do logocentrismo, mas, transportadas para um sistema de valores que lhes é em grande parte estranho, estas formas apontam para o problema sem the dar verdadeiro encaminhamento. No meu entender, com este gesto, substitui-se o absoluto da tradição ocidental pela nostalgia de um absoluto sensório-espiritual que o ocidente parece enxergar no oriente. 
Folhetim se insere nestas encruzilhadas, nestas articulaçōes entre a reflexão e o espetáculo, entre a criação e o pensamento sobre a criação. Editado por uma companhia de repertório, Folhetim reitera o interesse do Teatro do Pequeno Gesto pelo pensamento sobre a atividade teatral e pela formação de platéias e procura oferecer, de forma continuada, capitulos sobre tópicos importantes para o trabalho cênico, optando pela variedade temática e pelo ecletismo dos enfoques como forma de apresentar a multiplicidade e a riqueza do mundo que gira em torno dos palcos.

Para escolher os artigos veiculados, Folhetim tem como princípio orientador o viés ensaístico, isto é, o desenvolvimento de uma estrutura de reflexão que tenha como espinha dorsal uma questão. Pensar criticamente é perguntar pelo sentido das coisas. Aprender que esta atitude deve presidir nossa prática é, ou deveria ser, um dos objetivos de nossa trajetória como viventes e, evidentemente, como profissionais de teatro.

Isto nos livraria de alguns percalços: o primeiro deles é o utilitarismo com que a reflexão é encarada - como uma espécie de repositório de soluçōes ou receitas que podem ser transpostas mecanicamente para nossa atividade teatral. A elaboraçāo teórica é, muitas vezes, sumariamente desvalorizada se nela não se vê uma imediata aplicação ao trabalho cotidiano de criação. $O$ jogo que pode ser desenvolvido entre quem elabora criticamente uma questão e quem está às voltas com a estruturação de um personagem ou de um cenário, por exemplo, parece escapar ao leitor desatento ou táo autocentrado que não percebe a analogia entre estes processos criativos.

Um segundo percalço é o medo que os artistas têm da formalização do pensamento, acreditando que isto fará "secar a inspiraçáo", o que vem ao encontro do que falávamos há pouco a respeito do mito da espontaneidade da arte do ator (e que inclui a suposta co-materialidade entre ator e personagem). É preciso repetir sempre: toda prática criativa manifesta um modo de pensar a criação e é uma elaboração altamente sofisticada que não pode prescindir do reconhecimento e da explicitação de seu subtexto. Reconhecer isto fertiliza o trabalho, desde que se tenha persistência suficiente para ultrapassar a franja da facilidade, do "é assim porque eu sinto assim" e tantas outras expressóes familiares a quem lida com o dia-a-dia da criação teatral. Não é o excesso de pensamento o que paralisa o trabalho, mas a falta dele.

Por fim, é preciso também reconhecer que muitas elaborações teóricas que têm o teatro como objeto não se dão sequer ao trabalho de estabelecer elos entre o domínio propriamente teatral e o aparato crítico que lhes serve de moldura e que, muitas vezes, provém de outros domínios do pensamento. Como arte espáciotemporal, o teatro solicita uma análise interdisciplinar, mas é preciso não perder de vista que a atividade teatral deve ser o crivo pelo qual todos estes aportes devem passar, caso contrário, desconsiderado em sua especificidade, o teatro se torna mero exemplo de teorias alheias a ele.

A revista Folhetim reverbera também a presença de uma dramaturgista na companhia: a necessária circulação entre os três objetivos principais do Teatro do Pequeno Gesto - a criação de espetáculos, as oficinas e a editoria da revista - tem como vértice a preocupaçáo de aprender a pensar e manifestar isto de forma compreensível para espectadores e leitores. Aprender a pensar teatro. Aprender a pensar teatralmente. Tornar o pensamento visível ali onde se pensa que ele é "natural". 


\section{Referências Bibliográficas}

ARGAN, Giulio Carlo. Arte e crítica de arte. Trad. Helena Gubernatis. Lisboa, Estampa, 1993. BARTHES, Roland. L'obvie et l'obtus. Paris, Seuil, 1982.

BORNHEIM, Gerd. Páginas de filosofia da arte. Rio de Janeiro, Uapê, 1998.

RILKE, Rainer Maria. Sobre a paisagem. Trad. de Alberto Tibaji. Mimeo, 1988.

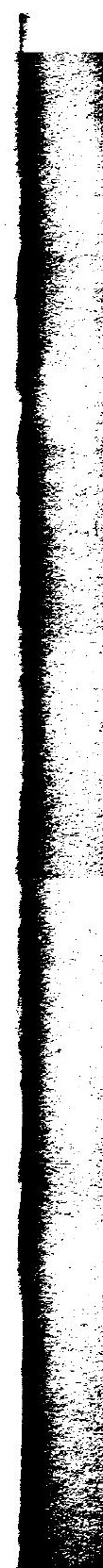

